\title{
High Performance of Sulfur/Carbon Cathode Synthesized Via a Facile Green Microwave Approach
}

Hanxue Xu, ${ }^{1,2}$ Junwei Hao ${ }^{1}$, Yao Chen ${ }^{1}$, Hairui You${ }^{1}$ and Xiaomin Liu ${ }^{* 1}$ and Hui Yang ${ }^{* 1}$

${ }^{1}$ College of Materials Science and Engineering, Nanjing Tech University, Nanjing, 210009, Jiangsu, China.

${ }^{2}$ Skysource Nanjing Powertrain Technology Co. Ltd., Nanjing, 211300, Jiangsu, China.

${ }^{*}$ Corresponding authors

E-mail address: liuxm@njtech.edu.cn (X. Liu); yanghui@njtech.edu.cn (H. Yang).
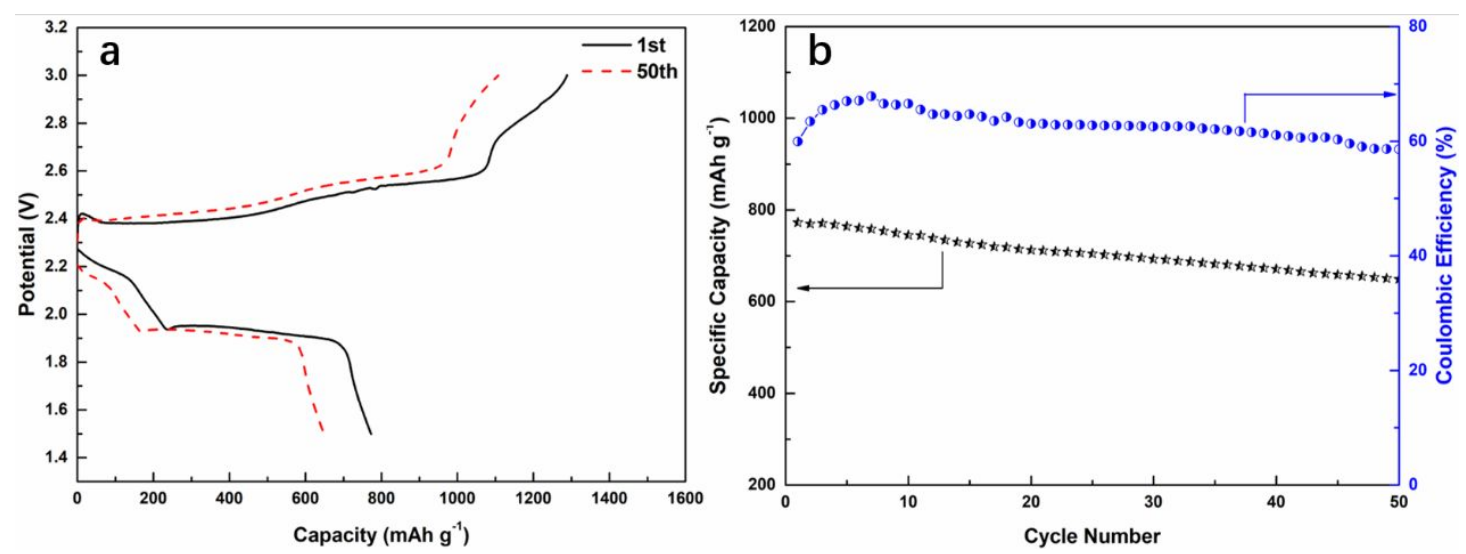

Figure S1. (a) The charge/discharge behaviors of the first and fiftieth cycle at $0.2 \mathrm{C}$; (b) Cycle life test of B-S/C composite at $0.2 \mathrm{C}$ 


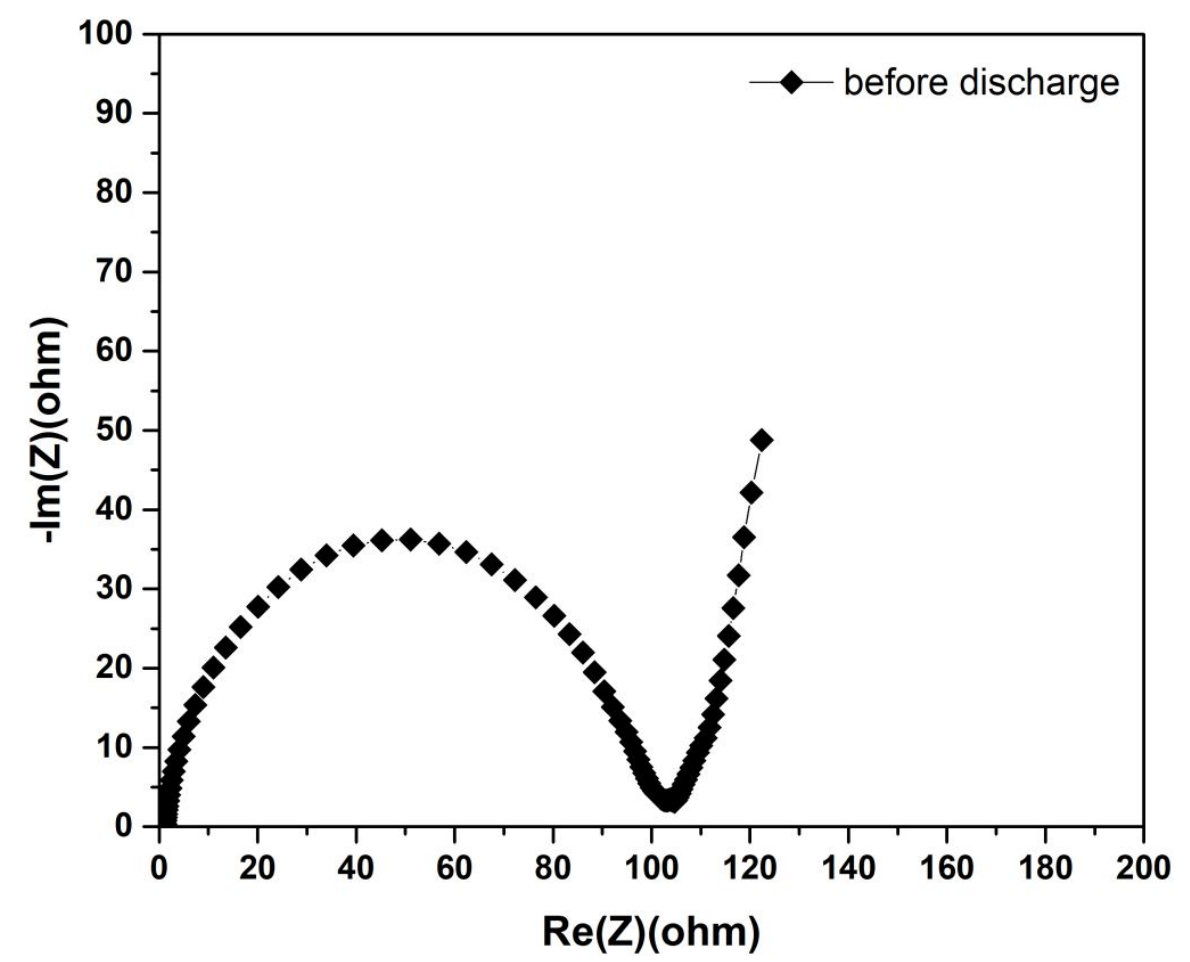

Figure S2. Electrochemical impedance spectra (EIS) of B-S/C cell before charge/discharge test

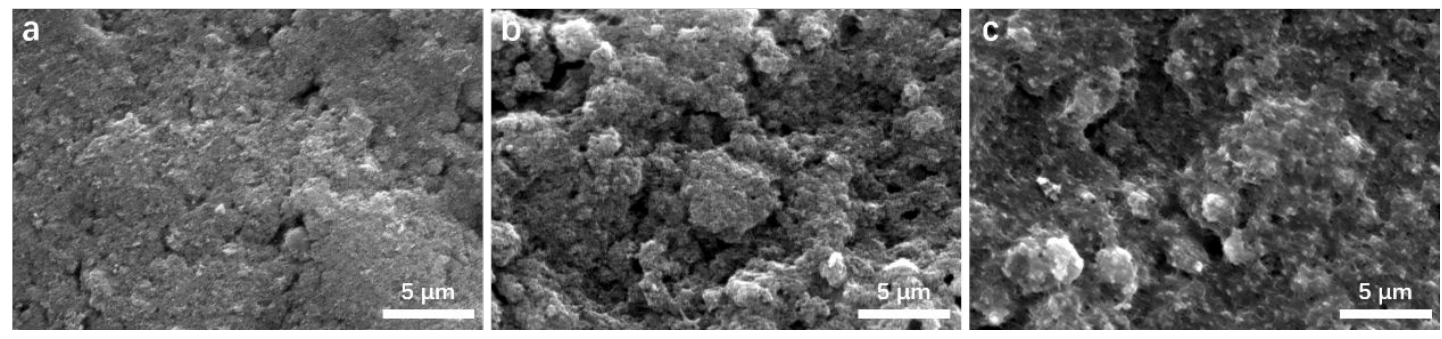

Figure S3. SEM images of aged B-S/C (a), H-S/C (b) and M-S/C (c) cathode at fully discharged state collected from the cells cycled at $0.2 \mathrm{C}$ for 50 cycles 